\title{
Cî̂nCIas Econômicas
}

\section{Esforço fiscal e ônus político nas cidades médias: o desempenho de Vitória da Conquista na arrecadação do IPTU}

\author{
Roberto Paulo M. Lopes ${ }^{1}$ \\ Ivo Costa Novais ${ }^{2}$ \\ Jonathan Iraías Vieira Lopes ${ }^{3}$
}

\begin{abstract}
Resumo: Este estudo tem por objetivo analisar o desempenho de Vitória da Conquista na arrecadação do Imposto Predial e Territorial Urbano (IPTU), considerando o potencial do município e o esforço do governo local. A hipótese subjacente é a de que o fraco desempenho em relação ao IPTU decorre do ônus político da cobrança desse tipo de tributo e da importância das transferências intergovernamentais no conjunto das receitas da prefeitura. A análise fundamenta-se na Teoria da Escolha Pública (TEP) e nos parâmetros de Tristão (2003), que emprega o método Análise de Cluster para avaliar e classificar o comportamento tributário dos municípios brasileiros. Os resultados apontam um esforço fiscal reduzido do governo municipal e, portanto, um fraco desempenho de Vitória da Conquista na arrecadação do IPTU.
\end{abstract}

Palavras-chave: Desempenho fiscal. Imposto. Transferências intergovernamentais. Ônus político.

Abstract: This study aims to analyze the performance of Vitória da Conquista municipality in the collection of property tax - IPTU - considering its potential and the fiscal effort of the municipal government. The underlying hypothesis is that the poor performance in property tax collection stems from the political burden to the collection of this type of tax, and the importance of intergovernmental transfers in the revenue of the city, which makes irrelevant the fiscal effort. The basic theory used to support the analysis of the arguments is the Theory of Public Choice (TEP). To analyze the performance of the municipality in tax revenue, used the defined parameters set by Tristão (2003), employing the Cluster analysis as a method to classify and assess the tax behavior of brasilian municipalities. The results point to a low tax effort that results in poor performance in collecting the property tax.

Keywords: Fiscal performance. Tax. Intergovernmental transfers. Political cost.

\section{Introdução}

Entre as razões que explicam e validam o federalismo fiscal brasileiro, o Imposto Predial e Territorial Urbano (IPTU) é um caso paradigmático quando se trata de competência tributária.

${ }^{1}$ Doutor em Geografia, Planificación Territorial i Gestión Ambiental pela Universidade de Barcelona. Mestre em Economia pela Universidade Federal da Bahia. Professor Adjunto da Universidade Estadual do Sudoeste da Bahia (UESB). Líder do grupo de pesquisa (CNPq) “Políticas Educacionais e de C\&T para Superação das Desigualdades Regionais na Bahia”. E-mail: rpm.lopes@ hotmail.com

${ }^{2}$ Graduando em Economia pela Universidade Estadual do Sudoeste da Bahia (UESB). E-mail: ivoabaira@hotmail.com ${ }_{3}^{3}$ Graduando em Economia pela Universidade Estadual do Sudoeste da Bahia (UESB). E-mail: jhow_nathan16@hotmail.com

Cadernos de Ciências Sociais Aplicadas

Vitória da Conquista

Ano XIV

n. 23

p. $1-16$

2017 
Diferentemente das bases móveis (a renda, por exemplo), que requerem certo grau de centralização administrativa, a propriedade imobiliária tem uma base de cálculo que não permite migração. Ainda que bem caracterizado e sem competências concorrentes, o IPTU materializa-se de forma desigual nos municípios brasileiros, com grandes variações na arrecadação per capita e problemas de ordem econômica, política e administrativa no seu recolhimento. Tais dificuldades interferem na participação desse imposto na carga tributária brasileira. Em 2014, o IPTU correspondeu a 1,51\% da receita nacional e a apenas $0,51 \%$ do Produto Interno Bruto (PIB). No Reino Unido, Canadá e Japão, ele representa mais de 3\% do PIB e contribui com algo em torno de $9 \%$ da receita total de impostos (TRISTÃO, 2003).

Apesar do fraco desempenho no Brasil, o Imposto Predial e Territorial Urbano é uma importante fonte de financiamento de políticas públicas dos governos municipais em todo o mundo, especialmente nos países desenvolvidos. Não obstante sua importância para as economias locais e para os sistemas tributários de diversos países, são escassos os estudos científicos que investigam as razões de sua aplicação desigual nas cidades brasileiras e de sua pouca contribuição para a arrecadação nacional. Embora o Brasil tenha uma das mais altas cargas tributárias do mundo, os impostos sobre a propriedade imobiliária estão bem abaixo da média mundial. Uma das hipóteses para o desinteresse e para o baixo desempenho na arrecadação do IPTU, especialmente nos pequenos e médios municípios, está nas formulações de Tristão (2003). Trata-se das fontes de receitas, originárias das transferências intergovernamentais, as quais desestimulariam o esforço fiscal dos governos municipais, livrando os governantes do ônus político inerente à cobrança desse imposto.

$\mathrm{Na}$ condição de fonte de financiamento, o IPTU tem uma representação heterogênea nos municípios brasileiros. Em São Paulo, por exemplo, seu valor significa um terço das receitas e é cerca de vinte vezes maior que o do Fundo de Participação dos Municípios (FPM). Em municípios do interior do Nordeste, ao contrário, ele é residual e só é cobrado para que os prefeitos não se sujeitem às penalidades previstas na legislação. Além disso, em municípios muito pequenos, a estrutura para a arrecadação pode ter um custo superior às receitas. Outro aspecto que reforça a importância do IPTU é sua inelasticidade em relação às crises cíclicas. O fato de ter uma base imóvel, que não se ajusta com a mesma velocidade dos ciclos econômicos, torna esse imposto uma fonte de receita com maior estabilidade. Situação distinta ocorre com impostos muito sensíveis às variações no produto. É o caso daqueles que incidem sobre serviços, renda, produção e circulação de mercadorias. Nas fases ascendentes da atividade econômica, o desempenho do IPTU é, pelo menos no curto prazo, inferior ao dos demais tributos. Entre as principais razões geralmente aceitas para explicar esse fato estão: o ônus político da insatisfação dos eleitores e a ineficiência administrativa. Tais motivos são válidos apenas para os pequenos municípios, visto que não justificam o esforço fiscal apresentado pelas cidades médias.

Com o intuito de contribuir para o aprofundamento teórico-prático do debate e, subsidiariamente, auxiliar na formulação de políticas públicas, este estudo baseia-se em uma investigação sobre o desempenho na arrecadação do IPTU em Vitória da Conquista, cidade média do interior nordestino com um desenvolvido núcleo urbano. Familiar aos autores, o município conta com grupos de pesquisa locais, cujo objetivo é produzir informações que possam subsidiar políticas públicas e estratégias empresariais. A pesquisa concorre, portanto, para a adição líquida de conhecimentos sobre a realidade socioeconômica de Vitória da Conquista.

O objetivo deste estudo é verificar o desempenho de Vitória da Conquista na arrecadação do IPTU, considerando o potencial desse tributo e o esforço fiscal da prefeitura. A análise estabelece 
um paralelo entre os indicadores de Vitória da Conquista e os de outros municípios. IPTU per capita, taxa de crescimento anual das receitas, participação relativa nas receitas dos municípios e no produto municipal, são dados que permitem inferir o poder desse tributo. A hipótese subjacente é a de que o fraco rendimento na sua arrecadação decorre do ônus político ocasionado pela cobrança desse tipo de imposto e da importância das transferências intergovernamentais no conjunto das receitas da prefeitura, condição que tornaria irrelevante o esforço fiscal. Para a investigação, foram utilizados os parâmetros de Tristão (2003), que se serviu do método Análise de Cluster para classificar e avaliar o comportamento dos municípios no tocante à questão tributária.

Além desta introdução, este estudo se estrutura em mais cinco seções. A seguir, é feita uma breve revisão de literatura sobre a Teoria da Escolha Pública, além da apresentação das bases conceituais do federalismo fiscal brasileiro. A terceira seção classifica o município de Vitória da Conquista de cidade média, mostra os aspectos econômicos e os indicadores de finanças públicas. $\mathrm{Na}$ seção seguinte, descrevem-se a base de dados e a metodologia utilizada. A quinta seção analisa os resultados observados. A última seção traz as principais conclusões do estudo.

\section{Breve relato sobre a Teoria da Escolha Pública e as bases conceituais do federalismo fiscal}

A partir da segunda metade do século passado, a relação entre Estado e economia pautou-se no debate sobre a eficiência alocativa entre mercado e Estado. A crença no mercado sofreu um revés com a Grande Depressão da década de 1930, acontecimento que colocou em cheque os pressupostos da economia liberal. A crise ocasionou a emergência de ideias fundamentadas na imperfeição dos mercados e que justificavam a intervenção corretiva do Estado na economia, o estado de bemestar social (welfare state). As novas ideias, aliadas às evidências empíricas, dominaram o pensamento econômico por quase quarenta anos e forneceram a base científica para uma crescente participação do Estado na economia. Os abusos no intervencionismo ocasionaram, na década de 1970, uma nova crise econômica, abalaram a fé no estado de bem-estar social e fizeram ressurgir as ideias liberais que reduziram o papel do Estado. Entre as principais teorias que sustentam a crítica a esse modelo destaca-se a Teoria da Escolha Pública (TEP), que aponta não para menos Estado (como querem os liberais), mas para um Estado melhor.

Na perspectiva da teoria da escolha pública, trata-se de comparar os "fracassos do governo" com os "fracassos do mercado", ou seja, perceber que, quer o mercado, quer o sector público, são instituições imperfeitas de afectar os recursos, e como tal o objectivo da análise é desenvolver uma análise institucional comparada (PEREIRA, 1997, p. 438).

Sem a pretensão de apresentar um modelo alternativo, a Teoria da Escolha Pública (TEP) parte da análise dos fracassos do governo. Segundo ela, a política tem falhas e as decisões tomadas coletivamente nem sempre alcançam o bem-estar geral (BERNABEL, 2009).

Deixando de lado a influência da teoria hobbesiana do Estado, a TEP desenvolveu-se nas décadas de 1950 e 1960, com a concepção de que o indivíduo é um componente fundamental e de que os indivíduos agem para satisfazer às suas vontades e não a uma vontade geral. Tais quais no mercado, as decisões em política baseiam-se no autointeresse, não procuram o benefício dos outros, mas o próprio benefício (PEREIRA, 1997). Na TEP, os conceitos de economia de mercado aplicam- 
se à política e aos serviços públicos. O foco das decisões políticas não é o interesse público em geral, na condição de agentes humanos, os políticos priorizam a satisfação do autointeresse. A TEP expõe os problemas relacionados à tomada de decisão coletiva e evidencia as seguintes falhas de governo e do sistema político: ineficiência da administração pública, rigidez institucional, permeabilidade à atuação de lobbies e interesses eleitoreiros.

Alguns desses problemas podem ser utilizados para explicar o baixo desempenho de alguns municípios brasileiros na arrecadação do IPTU. Para preservar o poder, muitos prefeitos optam por evitar o ônus político inerente à cobrança desse tributo e, dessa forma, causam dano à coletividade em benefício próprio. Outro aspecto que contribui para o enfraquecimento da ação de cobrança do IPTU relaciona-se à falta de atualização do valor venal dos imóveis. Além da pressão dos contribuintes, nos municípios pequenos, os grandes proprietários de imóveis são geralmente os políticos, situação que compromete ainda mais o esforço fiscal. Os impostos sobre a propriedade são mais vulneráveis à manipulação política e à influência dos grandes proprietários, especialmente nos pequenos e médios municípios. Esse fato expõe a predominância do interesse pessoal em detrimento do coletivo.

Uma prática comum em pequenos e médios municípios brasileiros é a liberalidade nas isenções e anistias. O uso deliberado de tal dispositivo, cujo objetivo é favorecer determinados segmentos da sociedade, tem fins políticos e visam à autossatisfação e não ao interesse público em geral. A renúncia de receitas decorrentes da liberalidade na concessão das isenções traduz-se na redução de obras e serviços públicos que deveriam beneficiar a coletividade. A TEP contribui para evidenciar o papel dos grupos de interesse na influência e na definição das políticas públicas e expõe a incapacidade do governo para conhecer e satisfazer as preferências da coletividade.

\subsection{Federalismo fiscal e competências tributárias}

A descentralização política, administrativa e fiscal tem por fim potencializar a função alocativa do setor público e as funções estabilizadora e distributiva. Estruturado sob a forma federativa, o Estado se organiza redistribuindo o poder e a autonomia entre os diferentes níveis de governo, atribuindo-lhes competência para tributar e instituindo as respectivas fontes de receitas. A eficiência alocativa pressupõe o fornecimento de bens públicos, considerando as preferências dos habitantes de um município, por exemplo. Tais benefícios devem ser financiados pela comunidade beneficiada (MUSGRAVE, R. A.; MUSGRAVE, P. B., 1980). Por ter uma base imóvel, o IPTU é um caso clássico de função alocativa, por isso sua fonte de recursos deve se direcionar para melhorias locais. Uma vez que as cidades são economias abertas e alguns impostos têm base móvel, a competência para tributar deve ser de um governo central, que, por meio das transferências intergovernamentais, valida as funções distributiva e estabilizadora.

A divisão de competências tributárias entre os níveis de governo visa à estruturação de um sistema menos distorcido em termos de eficiência alocativa. Alguns impostos requerem certo grau de centralização, outros (o que incide sobre a propriedade imobiliária, por exemplo) não permitem migração, visto que são de competência dos governos locais. As restrições (legais, técnicas e econômicas) nas competências para tributar geram uma distorção na relação entre as fontes de arrecadação e os responsáveis pelo atendimento imediato das demandas sociais. Essas distorções são compensadas pelas transferências intergovernamentais, utilizadas para reduzir as desigualdades regionais. A repartição da competência tributária no Brasil, definida pela Constituição de 1988, é complexa e acentua a 
centralização. Mais de 2/3 dos impostos arrecadados no Brasil são de competência da União e menos de 7\% compete aos municípios, conforme dados do Centro de Estudos Tributários e Aduaneiros (CETAD) (BRASIL, 2015a). A complexidade envolve diferentes tipos de competência tributária: privativas, comuns e concorrentes. Em seu artigo 30, inciso I, a Constituição Federal de 1988 estabelece de forma privativa competência para os municípios instituir impostos sobre a propriedade territorial e urbana, sobre as transmissões de bens inter vivos (ITBI) e sobre os serviços de qualquer natureza (ISS). Há um consenso na literatura de que os tributos mais adequados para o nível local são aqueles que incidem sobre a propriedade imobiliária (TRISTÃO, 2003).

A repartição de competências na Constituição de 1988 alinha-se à teoria tradicional das finanças públicas e se estrutura consoante o federalismo de equilíbrio. Compete ao governo federal arrecadar impostos que requerem certo grau de centralização administrativa e aqueles utilizados na formulação das políticas econômicas. Aos governos locais compete tributar o patrimônio físico. Os impostos sobre consumo e circulação de bens são de atribuição dos estados - nível intermediário. A repartição de competências não garante, no entanto, o equilíbrio federativo, de modo que a disparidade entre as fontes de arrecadação e as obrigações de despesas funcionais entre os diferentes níveis da federação são compensadas pelas transferências intergovernamentais. Estas se originam nos níveis superiores de governo e se orientam para os níveis inferiores. Além de propiciar mais equidade à estrutura de tributação, elas servem de instrumento para corrigir as desigualdades regionais. A principal transferência para os municípios vem da União. Trata-se do Fundo de Participação dos Municípios (FPM). Do total de recursos do fundo, $86,4 \%$ são repartidos de forma regressiva, beneficiando com maior proporção os municípios menos populosos. Assim, quanto menor o município, maior a significância do FPM para as receitas municipais e menor o esforço na arrecadação dos tributos de sua competência. Cabe destacar que os municípios médios têm um critério adicional no rateio desse Fundo.

\subsection{O IPTU no contexto da estrutura tributária brasileira}

A estrutura tributária brasileira é recheada de iniquidades. Problemas com regressividade, a incompatibilidade entre o tamanho da carga e a renda média do brasileiro e a qualidade dos serviços públicos dominam a agenda de debates sobre o tema. Mais da metade da arrecadação nacional vem de impostos indiretos que são embutidos nos preços dos bens e serviços. Isso reduz a percepção do contribuinte sobre o peso da carga de impostos, diferentemente da maioria dos países desenvolvidos, que tem nos impostos indiretos apenas um quarto de suas receitas, visto que o restante se origina da tributação sobre a renda e a propriedade. Por ser direto, o IPTU, é alvo de críticas mais contundentes e da revolta dos contribuintes, que veem a possibilidade de cotejar o tributo pago com os benefícios recebidos. "Em tal contexto, o IPTU - o mais explícito dos tributos brasileiros - acaba sendo o 'bode expiatório' da revolta do contribuinte” (AFONSO; ARAÚJO; NÓBREGA, 2013).

Enquanto os países de língua inglesa têm preferência por impostos diretos, os países latinos optam pela tributação indireta, o que interfere no grau de participação (maior ou menor) desse tributo na receita dos países. Os Estados Unidos lideram a arrecadação dos impostos diretos, que significam $9,82 \%$ da receita, correspondente a $2,77 \%$ da maior economia do planeta (TRISTÃO, 2003). Ou seja, considerando o produto americano de 2015, equivale a uma arrecadação próxima a meio trilhão de dólares, valor superior ao do PIB de 80\% dos países das Nações Unidas e maior 
que a receita tributária do governo federal brasileiro. No Brasil, o IPTU representa 1,51\% da receita tributária e apenas $0,51 \%$ do PIB.

O Código Tributário Nacional dispõe sobre o fato gerador, sujeito passivo, base de cálculo e alíquota do IPTU. Cabe a cada município fixar sua alíquota, geralmente em torno de $1 \%$. O valor venal, que serve de base de cálculo, pode ser obtido por meio de avaliações individuais ou pelo sistema de avaliações em massa - o caso mais comum - mediante a Planta Genérica de Valores (PGV). As deficiências no sistema de avaliação, aliadas à falta de interesse na atualização dos parâmetros e ao desprezo pelos aspectos dinâmicos que impactam a valorização dos imóveis, são fatores determinantes para o fraco desempenho dos municípios brasileiros na arrecadação desse tributo. Outro aspecto que contribui para tal performance se relaciona ao desinteresse quanto ao uso da progressividade na arrecadação do imposto. A Emenda Constitucional n ${ }^{\circ} 29$, de 13 de setembro de 2000, autoriza a progressividade na cobrança do IPTU. Além de haver questionamentos quanto à inconstitucionalidade da Emenda, não se verifica nenhum esforço dos médios e pequenos municípios para cumpri-la (BRASIL, 2000).

O reduzido esforço fiscal e, em consequência, o fraco desempenho na arrecadação do IPTU podem ser sentidos na falta de atualização da Planta Genérica de Valores e no cadastro predial e territorial urbano. Outro fator de destaque é o elevado grau de inadimplência. Segundo Tristão (2003), apenas 37,8\% dos municípios conseguiram atingir 60\% dos proprietários de imóveis.

\section{Vitória da Conquista: características e transformações recentes}

Vitória da Conquista é uma cidade média do interior do Estado da Bahia. A adjetivação "média" envolve uma escala de grandeza que, nesse caso, se relaciona ao contingente populacional. $\mathrm{Na}$ literatura, tanto no campo da geografia espacial como no da economia regional, cidade média no Brasil é aquela com contingente populacional entre cem mil e quinhentos mil habitantes. Segundo o Censo de 2010, a população do município era de 306.374 habitantes, 89,7\% concentrados na área urbana. A estimativa do IBGE para 2014 é de 340.199 pessoas (IBGE, 2014). Contudo, há necessidade de ir além do contingente populacional e levar em conta o papel que a cidade desempenha em sua região de articulação. Sua força centrípeta é a força exercida na sua área de influência (MAIA, 2010).

Além do aspecto populacional, Vitória da Conquista também recebe a classificação de cidade média por ter suas atividades diretamente relacionadas à função administrativa que exerce. O município tem capacidade de prover serviços e infraestrutura urbana básica (educação, saúde, saneamento, segurança, entretenimento, entre outras) e influenciar a atividade econômica do seu entorno. A categoria cidade média baseou-se na construção e na expansão de vias de comunicação, bem como na implantação de infraestrutura de transporte, nas décadas de 1950/1960, com a construção da Rio-Bahia (BR-116). O processo de formação de muitas cidades médias no Brasil, com vistas a uma efetiva interiorização e à criação de centros urbanos intermediários dinâmicos, ocorreu mediante a ligação com metrópoles, em um contexto de deseconomias de aglomeração nas metrópoles.

$\mathrm{Na}$ condição de cidade média, Vitória da Conquista possui a função de articular os centros do capital e de comando aos menores centros urbanos. A elevada presença de bens e serviços, que só podem ser oferecidos em lugares centrais, torna a cidade privilegiada entre os municípios baianos. Ao longo dos últimos anos, ela concentra bens públicos considerados agentes de urbanidade. Entre esses 
bens destacam-se a Universidade Estadual do Sudoeste da Bahia, o Instituto Federal de Educação e, mais recentemente, um campus da Universidade Federal da Bahia. Portanto, além do crescimento populacional, o município dispõe de um conjunto de relações políticas, culturais, econômicas e sociais com a sua região de influência, ou seja, de aspectos quantitativos e qualitativos que lhe conferem a condição de cidade média. Desde a sua origem, Vitória da Conquista exerce uma forte centralidade, em uma inserção constante e duradoura, tanto no seu espaço regional quanto nos aglomerados de hierarquia superior. Sposito (2009) destaca as características de uma cidade média. Verifica-se a presença de tais atributos na relação de Vitória da Conquista com sua região de influência.

[...] cidades que comandam uma região, que polarizam uma região, que crescem em detrimento da sua própria região ou crescem em função da sua própria região, as duas coisas acontecem. Cidades médias que ampliam seus papeis, porque diminuem os papeis das cidades pequenas a partir de uma série de mecanismos econômicos, ou cidades que, em função do tipo de atividade que têm, das lideranças que ali se encontram, são capazes de crescer e propor um projeto ou desempenhar um papel político, econômico e social de crescimento para toda uma região (SPOSITO, 2009, p. 19).

Até a década de 1940, a economia de Vitória da Conquista fundava-se na pecuária extensiva. A partir daí, a estrutura econômica e social do município entra em um novo estágio e o comércio ocupa um lugar de grande destaque na economia local. Em função de sua privilegiada localização geográfica e graças à abertura da BR-116 e das rodovias estaduais BA-415 e BA-262, o município incorporou-se a outras regiões do Estado e ao restante do País. Essa relação com as economias nacional e estadual elevou o município à condição de centro comercial regional.

A evolução econômica de Vitória da Conquista acompanha, nos seus grandes traços, a trajetória do desenvolvimento econômico brasileiro, apesar de o município manter-se distante dos centros de decisão e desconectado dos núcleos de reprodução da economia capitalista. No início da década de 1970, dois setores são introduzidos na economia local: a cafeicultura e uma incipiente indústria de transformação. A partir do final da década de 1980, a economia passa a sustentar-se fundamentalmente do setor de serviços e do comércio, com destaque para a atividade varejista. $\mathrm{O}$ crescimento dos setores comercial e de serviços (principalmente educação e saúde), na década de 90, contribuiu para manter a estabilidade econômica do município. Os serviços representam mais de $80 \%$ do valor adicionado do produto municipal. Em 2013, a estimativa da SEI (2014) é de cerca de 5 (cinco) bilhões de reais, o que representa 2,42\% do produto estadual.

A prestação de serviços é a atividade econômica que mais cresce em Vitória da Conquista. Até o início dos anos 1990, esse setor era dominado pelos serviços tradicionais, oficinas, marcenarias e alfaiatarias, por exemplo. A partir dos anos 1990, dois segmentos relacionados à economia dos serviços começam a se destacar. O primeiro, os serviços de educação, com uma oferta que se amplia e se diversifica continuamente, tanto na área pública, quanto na privada. O segundo segmento são os serviços de saúde, que também têm-se ampliado e desenvolvido nas últimas décadas e ocasionam um aumento relativo no número de leitos hospitalares, a diversificação dos serviços prestados e, principalmente, o surgimento de clínicas e laboratórios que utilizam, na sua maioria, tecnologia deponta.

As instituições do município e, especialmente, as do seu entorno têm uma atuação pouco expressiva. Isso explica parte das baixas taxas de desenvolvimento econômico e social da região. As 
instituições atuais mantêm as características do período da colonização, com uma estrutura produtiva ineficiente e uma administração burocrática. A inércia desses organismos ocasionou, ao longo do tempo, algumas práticas como a violência política, o coronelismo, a corrupção (tanto institucional quanto individual), o clientelismo e a troca de favores políticos. Tal estrutura garantiu a reprodução de regimes políticos decadentes (a oligarquia, por exemplo), à medida que o coronelismo estabelece uma interface entre os interesses políticos locais e os interesses políticos em escala nacional. Nessa relação, interesses paroquiais, de deputados e das elites dominantes em escala nacional se entrelaçam (LOPES, 2009). Nem o regime autoritário nem a democracia eleitoral moderna, com a ascensão de partidos que se opunham a essa prática política, foram capazes de romper tal estrutura. Ao contrário, aliaram-se a ela.

\subsection{Finanças municipais}

Apesar de o processo político atual ainda reproduzir vícios históricos, após 1996, ocorreu uma transformação na política de Vitória da Conquista, cuja estrutura se distancia das práticas comuns à grande maioria dos municípios brasileiros. Assim, houve uma melhoria na qualidade das instituições e isso influencia a organização e os equipamentos públicos. Além das mudanças na forma de fazer política, destaca-se o Orçamento Participativo, uma experiência iniciada em 1997. A administração tributária também passou por transformações com a adesão da prefeitura ao Programa de Modernização Tributária e da Gestão dos Setores Sociais Básicos (PMAT). Tal programa foi criado em 1997 pelo governo federal com o objetivo de fomentar a modernização da administração tributária e promover melhorias na qualidade do gasto público, com linhas de financiamento destinadas à aquisição de equipamentos, capacitação de recursos humanos e serviços técnicos especializados, entre outras. Outro objetivo do Programa para a melhoria da gestão é elevar a arrecadação dos impostos de competência municipal.

O orçamento da prefeitura de Vitória da Conquista para o exercício de 2014 foi de pouco mais de quinhentos e quarenta milhões de reais. Desse valor, 14,4\% representam receitas próprias do município; as transferências superam $75 \%$ das receitas totais. Tal como ocorre no Brasil de modo geral, no município em questão, o ISS tem o maior potencial de arrecadação, visto que contribui com $8,14 \%$ das receitas. Isso significa 56\%, ou seja, mais da metade das receitas próprias. Por ser indireto, com uma base de cálculo imponível e bem caracterizada, o ISS tem o recolhimento facilitado sem se sujeitar diretamente ao ônus (político) da cobrança dos impostos diretos.

Quadro 1 - Vitória da Conquista: composição das receitas municipais, 2013-2014.

\begin{tabular}{|c|c|c|}
\hline Vitória da Conquista & $\mathbf{2 0 1 3}$ & $\mathbf{2 0 1 4}$ \\
\hline Receita total & $\mathbf{4 9 8 . 3 1 7 . 2 7 9 , 7 8}$ & $\mathbf{5 4 0 . 2 3 2 . 3 6 0 , 1 9}$ \\
\hline Receita Própria & $71.182 .306,56$ & $77.939 .099,70$ \\
\hline Impostos Totais & $67.110 .332,83$ & $73.352 .573,64$ \\
\hline IPTU & $10.916 .734,99$ & $12.637 .615,94$ \\
\hline ISS & $41.633 .180,64$ & $43.965 .698,11$ \\
\hline Transferência Corrente & $386.741 .465,13$ & $413.985 .732,21$ \\
\hline FPM & $53.967 .946,57$ & $61.227 .561,76$ \\
\hline Quota ICMS & $64.698 .785,63$ & $70.143 .507,84$ \\
\hline
\end{tabular}

Fonte: Prefeitura Municipal de Vitória da Conquista (2014); STN (2015) e Bahia (2014). 
Apesar de ser um município de médio porte, Vitória da Conquista depende das transferências intergovernamentais, semelhante ao que ocorre com a grande maioria dos municípios do Nordeste brasileiro. Essa dependência torna o município refém da política econômica do poder central e reduz sensivelmente a capacidade dos poderes estadual e municipal de fazer política regional/local.

O IPTU representou apenas 2,34\% no conjunto das receitas do município, o que desestimula um esforço fiscal maior para a sua arrecadação. Em Vitória da Conquista o percentual cobrado sobre o valor venal do imóvel, seja comercial, industrial ou residencial, é de 1\%. Em 2014, o valor venal médio no município foi de $\mathrm{R} \$ 243,20$ (duzentos e quarenta e três reais e vinte centavos) por metro quadrado. Esse número é pelo menos quatro vezes menor do que o praticado em Salvador. Apesar de a renda per capita do conquistense ser bem inferior à renda média do brasileiro, evidencia-se a existência de um potencial de arrecadação de IPTU não explorado. A baixa arrecadação associa- se à falta de critérios condizentes com a realidade, no tocante à atualização da Planta Genérica de Valores e a deficiências no cadastro predial e territorial urbano. Conforme o anexo de metas fiscais da LOA (PMVC, 2014), a renúncia fiscal, isenção do imposto para a população de baixa renda, está estimada em quatrocentos e sete mil reais e representa pouco mais de 3\% do que foi arrecadado, não sendo, portanto, relevante para explicar o baixo desempenho fiscal.

\section{Metodologia e base de dados}

Para avaliar o desempenho de Vitória da Conquista na cobrança do IPTU, considerando sua capacidade e o esforço fiscal do governo municipal, foram constituídos alguns indicadores que permitissem confrontar a arrecadação do município em análise com a de cidades de médio e grande porte. A Análise de Cluster, fundamentada nos parâmetros definidos por Tristão (2003), complementou a investigação. Com base em um conjunto de técnicas multivariadas, agrupam-se os municípios em quatro clusters, divididos em dois clusters pequenos (1 e 2) e dois clusters grandes (3 e 4). Os clusters pequenos apresentam os melhores resultados na arrecadação dos tributos próprios. Os grandes são altamente dependentes das transferências intergovernamentais (TRISTÃO, 2003).

Foram utilizadas a média e a mediana de cada um dos agrupamentos definidos por Tristão (2003), que se serviu do programa MINITAB Statistical Software 13.0 para avaliar um conjunto de 4.617 municípios. O número de municípios do Brasil utilizados para classificar os clusters corresponde a $83 \%$ do total e ultrapassa $90 \%$ da população do país. Com base nos seus indicadores, Vitória da Conquista enquadra-se no limite de dois dos clusters definidos. Posteriormente, foram feitas inferências sobre o seu desempenho na arrecadação de IPTU e avaliado o grau de dependência em relação às transferências constitucionais (FPM e quota-parte do ICMS), as quais desestimulam o esforço fiscal. A tipologia utilizada na Análise de Cluster permite distinguir, entre os municípios, os "bons arrecadadores", aqueles que utilizam de forma eficiente sua base tributária, e os "maus arrecadadores".

Tristão (2003) descreveu com propriedade e assinalou os caracteres dos clusters. Cluster 1 reúne os bons arrecadadores de IPTU, aqueles municípios que exploram melhor os recursos próprios e, em decorrência disso, mantêm reduzida a dependência das transferências governamentais. Nesse grupo, o IPTU é a principal fonte de receita, cujo valor é bem superior ao FPM e à quota-parte do ICMS. O cluster 1 abrange 40 municípios (0,87\% da amostra). Cluster 2 - reúne 67 municípios (1,45\% da amostra) que mantêm uma característica marcante: a arrecadação de recursos próprios, 
sem a predominância do imposto sobre a propriedade predial e territorial, com destaque para o Imposto Sobre Serviços (ISS). Cluster 3 - agrupa municípios com fraco desempenho na arrecadação de tributos próprios e que dependem das transferências, especialmente da quota-parte do ICMS para a composição da receita total. São 655 municípios com essa classificação (14,19\% da amostra). Por último, o Cluster 4 reúne os municípios com desempenho muito fraco, uma arrecadação residual de tributos próprios e uma grande dependência das transferências governamentais, especialmente o FPM. São 3.855 municípios com essa descrição (83,50\% da amostra).

Outros indicadores complementaram a análise e permitiram concluir sobre o uso (in)eficiente da sua base tributária e o (des)estímulo fiscal decorrente da importância das transferências nas receitas próprias. Tais indicadores são: IPTU per capita; participação no produto municipal; participação na composição das receitas dos municípios selecionados. Para avaliar o desempenho de Vitória da Conquista nos quesitos acima, foram selecionados os seguintes municípios: Campina Grande, Feira de Santana e Montes Claros, Salvador e São Paulo. O estudo abrangeu, portanto, médios e grandes municípios.

Serviram de fonte para reunir os dados de maior agregação de importância os relatórios do CETAD do Ministério da Fazenda. As informações relativas às finanças dos municípios selecionados foram obtidas em cada um dos domínios do portal da transparência e por meio do Finanças do Brasil (FINBRA). Os dados do FINBRA referem-se aos municípios brasileiros. A base é disponibilizada anualmente pela Secretaria do Tesouro Nacional (STN). A fonte dos elementos relativos ao produto dos municípios analisados foi o Instituto Brasileiro de Geografia e Estatística (IBGE). Calculou-se o PIB municipal com base na participação relativa do município no PIB nacional em 2011 (última publicação do IBGE). Aplicou-se o percentual encontrado sobre o PIB brasileiro divulgado pelo IBGE para o ano de 2014 (o cálculo foi de 5,69 trilhões).

\section{Análise e resultados}

Um indicador importante para comparar o desempenho dos municípios refere-se ao IPTU per capita. Conforme os dados do quadro abaixo, a arrecadação em Vitória da Conquista é menos de um terço da nacional e bem inferior ao valor de São Paulo e Salvador, por exemplo. Mesmo com renda per capita inferior, nos municípios médios, os valores praticados revelaram um fraco desempenho desse tributo que, pelo fato de ser direto, segundo a lógica da TEP, tem justificado o baixo esforço na arrecadação.

Quadro 2 - Arrecadação per capita de IPTU, Brasil e municípios selecionados - Em Reais.

\begin{tabular}{|l|r|r|r|r|r|}
\hline \multicolumn{1}{|c|}{ MUNICÍPIO } & \multicolumn{1}{c|}{$\mathbf{2 0 1 0}$} & \multicolumn{1}{c|}{$\mathbf{2 0 1 1}$} & \multicolumn{1}{c|}{$\mathbf{2 0 1 2}$} & \multicolumn{1}{c|}{$\mathbf{2 0 1 3}$} & \multicolumn{1}{c|}{$\mathbf{2 0 1 4}$} \\
\hline Vitória da Conquista & 25,15 & 27,72 & 31,31 & 32,40 & 37,15 \\
\hline Campina Grande & 13,93 & 17,86 & 20,45 & 24,23 & 23,58 \\
\hline São Paulo & 359,81 & 400,46 & 441,91 & 460,85 & 501,33 \\
\hline Salvador & 74,35 & 90,83 & 98,06 & 99,09 & 307,42 \\
\hline Feira de Santana & 22,07 & 23,94 & 26,62 & 35,08 & 73,85 \\
\hline Montes Claros & 34,24 & 36,01 & 35,42 & 48,08 & 49,03 \\
\hline BRASIL & 91,45 & 100,04 & 108,40 & 121,70 & 138,02 \\
\hline
\end{tabular}

Fonte: Elaboração própria com base nos dados do IBGE (2015), FINBRA (2015b) e CETAD (BRASIL, 2015a). 
O Quadro 3, abaixo, apresenta a taxa de crescimento médio anual real do IPTU nos últimos anos e o crescimento real acumulado entre 2010 e 2014. Descontada a inflação média anual do período medida pelo IPCA - 6,16\% - em Vitória da Conquista, esse imposto teve um crescimento real médio anual de 6,63\%. O aumento pode ser associado à expansão da área urbana do município, em face do boom imobiliário experimentado pelas cidades brasileiras no período. Portanto, o crescimento não ocorreu em função de nenhuma tentativa de melhorar o desempenho fiscal nem da atualização da Planta Genérica de Valores. De modo geral, a série mostrou uma regularidade na variação anual, exceto em Feira de Santana e, especialmente, em Salvador, que apresentou uma inflexão, elevando a receita para 213\% entre 2013 e 2014. Tal fato ocorreu em função de um maior esforço fiscal com a atualização da Planta Genérica de Valores e outras medidas de gestão tributária. São Paulo apresentou a menor taxa de crescimento real, em decorrência de uma atualização frequente da tabela genérica de valores. Nesse município, o IPTU per capita é 3,6 vezes maior que o nacional. De acordo com a análise, quanto maior o porte do município, mais compensador é o esforço fiscal em relação ao ônus político.

Quadro 3 - Crescimento médio e acumulado (2010-2014) na arrecadação de IPTU em Vitória da Conquista e em municípios selecionados

\begin{tabular}{|l|r|r|}
\hline \multicolumn{1}{|c|}{ MUNICÍPIO } & \multicolumn{1}{c|}{$\begin{array}{c}\text { CRESCIMENTO REAL MÉDIO } \\
\text { ANUAL (\%) }\end{array}$} & \multicolumn{1}{c|}{$\begin{array}{c}\text { CRESCIMENTO REAL } \\
\text { ACUMULADO 2010-2014 }\end{array}$} \\
\hline Vitória da Conquista & 6,63 & 29,28 \\
\hline Campina Grande & 8,67 & 39,44 \\
\hline São Paulo & 3,77 & 15,95 \\
\hline Salvador & 37,09 & 253,16 \\
\hline Feira de Santana & 30,45 & 189,62 \\
\hline Montes Claros & 5,00 & 21,56 \\
\hline BRASIL & 6,33 & 27,83 \\
\hline
\end{tabular}

Fonte: Elaboração própria com base no FINBRA (2015b) e CETAD (BRASIL, 2015a).

Conforme aponta o Quadro 4, quanto maior o município, mais representativo é o IPTU no conjunto das receitas municipais. Municípios maiores são menos dependentes das transferências intergovernamentais, o que resulta em um esforço fiscal maior. Esses dados ajudam, por oposição, a comprovar a hipótese formulada por Tristão (2003), segundo a qual as fontes de receitas propiciadas pelas transferências intergovernamentais desestimulariam o esforço dos governos de municípios menores.

Quadro 4 - Relação entre IPTU e Receita Total. Vitória da Conquista e municípios selecionados - em percentuais.

\begin{tabular}{|l|r|r|r|r|r|}
\hline \multicolumn{1}{|c|}{ MUNICÍPIO } & \multicolumn{2}{c|}{$\mathbf{2 0 1 0}$} & \multicolumn{1}{c|}{$\mathbf{2 0 1 1}$} & \multicolumn{1}{c|}{$\mathbf{2 0 1 2}$} & \multicolumn{1}{c|}{$\mathbf{2 0 1 3}$} \\
\hline Vitória da Conquista & 2,43 & 2,26 & 2,22 & 2,24 & 2,34 \\
\hline Campina Grande & 1,16 & 1,35 & 1,44 & 1,59 & 1,36 \\
\hline São Paulo & 13,50 & 14,12 & 14,43 & 14,45 & 14,65 \\
\hline Salvador & 6,62 & 6,78 & 6,91 & 6,44 & 17,52 \\
\hline Feira de Santana & 2,37 & 2,38 & 2,30 & 2,86 & 5,38 \\
\hline Montes Claros & 2,90 & 2,85 & 2,32 & 3,00 & 2,75 \\
\hline BRASIL & 1,38 & 1,35 & 1,37 & 1,40 & 1,51 \\
\hline
\end{tabular}

Fonte: Elaboração própria com base FINBRA (BRASIL, 2015b). 
Em 2000, do total da receita de 4.617 municípios (83,87\%), o Imposto Predial e Territorial Urbano representou 6,6\% e o ISS 7,9\% (TRISTÃO 2003). Considerando que a participação relativa não se altera muito ao longo do tempo, e, ao observar um conjunto numeroso de municípios, verificase quão residual é a participação do IPTU nas finanças públicas de Vitória da Conquista e quão fraco é o desempenho do município na sua arrecadação. O imposto está abaixo da média no total das receitas (2,34\%). Por outro lado, o ISS contribui com 8,14\% do total das receitas do município, revelando-se, portanto, o tributo de competência municipal com melhor desempenho fiscal. Por ser indireto, o IPTU reduz o ônus tributário e, consequentemente, o ônus político.

A relação entre IPTU e produto municipal reforça a hipótese de um menor esforço fiscal dos municípios dependentes das transferências intergovernamentais e de um maior esforço dos municípios menos dependentes. O quadro abaixo mostra a participação do Imposto Predial e Territorial Urbano no produto de Vitória da Conquista. Em 2014, ele significava menos da metade da sua representação no PIB brasileiro. Conforme se mencionou anteriormente, o Brasil tem um fraco desempenho na arrecadação de impostos sobre a propriedade imobiliária. Em alguns países, tributos com essas características chegam a ter uma participação superior a 3\% do produto. Em São Paulo e Salvador (que têm um melhor desempenho fiscal entre os municípios selecionados), a participação do IPTU no produto é superior a $1 \%$ do observado no Brasil e em muitos países desenvolvidos.

Quadro 5 - Relação entre IPTU e produto municipal. Vitória da Conquista e municípios selecionados - em percentuais.

\begin{tabular}{|l|r|r|r|r|r|}
\hline \multicolumn{1}{|c|}{ MUNICÍPIO } & \multicolumn{1}{c|}{$\mathbf{2 0 1 0}$} & \multicolumn{1}{c|}{$\mathbf{2 0 1 1}$} & \multicolumn{1}{c|}{$\mathbf{2 0 1 2}$} & \multicolumn{1}{c|}{$\mathbf{2 0 1 3}$} & \multicolumn{1}{c|}{$\mathbf{2 0 1 4}$} \\
\hline Vitória da Conquista & 0,221 & 0,224 & 0,250 & 0,221 & 0,252 \\
\hline Campina Grande & 0,124 & 0,130 & 0,145 & 0,148 & 0,143 \\
\hline São Paulo & 0,913 & 0,940 & 1,007 & 0,955 & 1,065 \\
\hline Salvador & 0,545 & 0,630 & 0,667 & 0,543 & 1,640 \\
\hline Feira de Santana & 0,164 & 0,163 & 0,175 & 0,196 & 0,411 \\
\hline Montes Claros & 0,275 & 0,272 & 0,246 & 0,263 & 0,274 \\
\hline BRASIL(1) & 0,450 & 0,450 & 0,460 & 0,470 & 0,510 \\
\hline
\end{tabular}

Fonte: Elaboração própria com base no, IBGE (2015) e FINBRA (BRASIL, 2015b). Brasil: relação entre IPTU e PIB (BRASIL, 2015).

Com base em alguns indicadores e em médias estabelecidas, o estudo comparou os valores alcançados em Vitória da Conquista com os clusters tipificados por Tristão (2003). Os valores aparecem no Quadro 6. O cluster 1 agrupa os municípios com melhor desempenho na arrecadação do IPTU. São cidades com atrativos turísticos e imóveis (prediais e territoriais) bem valorizados, cujos proprietários residem em outra localidade e os utilizam eventualmente. Nesse caso, uma vez que não haverá o ônus político da cobrança do imposto, tributam-se os não residentes. "Diante da impossibilidade desses proprietários expressarem sua insatisfação com a carga tributária no processo eleitoral, as autoridades locais se sentem mais confortáveis para tributar" (TRISTÃO, 2003, p. 163). Vitória da Conquista não reúne características tributárias nem urbanas para essa modalidade de cluster. 
Quadro 6- Indicadores selecionados: Vitória da Conquista e médias dos clusters.

\begin{tabular}{|l|r|r|r|r|r|}
\hline \multicolumn{1}{|c|}{ INDICADOR } & $\begin{array}{r}\text { Vitória da } \\
\text { Conquista }\end{array}$ & \multicolumn{1}{c|}{$\begin{array}{c}\text { Média } \\
\text { Cluster 1 }\end{array}$} & $\begin{array}{c}\text { Média } \\
\text { Cluster 2 }\end{array}$ & $\begin{array}{c}\text { Média } \\
\text { Cluster 3 }\end{array}$ & \multicolumn{1}{c|}{$\begin{array}{c}\text { Média } \\
\text { Cluster 4 }\end{array}$} \\
\hline IPTU/RT & 2,34 & 22,73 & 11,54 & 5,87 & 0,84 \\
\hline ISS/RT & 8,14 & 6,69 & 17,29 & 5,55 & 1,23 \\
\hline FPM/RT & 11,33 & 7,12 & 3,79 & 12,45 & 33,04 \\
\hline Quota-parte ICMS/RT & 12,98 & 14,64 & 20,24 & 26,93 & 22,00 \\
\hline
\end{tabular}

Fonte: Elaboração própria - média dos clusters calculada com base nas Estatísticas de Tristão (2003).

O cluster 2 agrupa os bons arrecadadores de ISS, ou seja, as metrópoles (cidades grandes, de hierarquia superior), que centralizam uma ampla base de serviços públicos e privados. Essa base de serviços amplia e valoriza o setor imobiliário, favorecendo a arrecadação de IPTU. Apesar da importância dos serviços, o pilar das finanças públicas dessas economias é a quota-parte do ICMS "em decorrência da intensidade das atividades industrial e comercial que caracterizam as regiões metropolitanas" (TRISTÃO, 2003, p. 164). Vitória da Conquista é uma cidade que tem o papel de articular os centros menores com os centros de hierarquia superior. Essa tarefa demanda centralização de saúde especializada, educação superior, serviços financeiros de média complexidade e outros. Contudo, em função da baixa participação do ISS e da quota-parte do ICMS, o município não reúne os requisitos do cluster 2 .

De forma semelhante, o cluster 3 reúne municípios com grande dependência da quota-parte do ICMS, porém com fraco desempenho na arrecadação dos tributos de sua competência. São municípios médios com atividade industrial e comercial intensa, mas que, provavelmente, pela proximidade geográfica com os grandes centros não desenvolveram uma base de serviços sólida nem dispõem de uma estrutura urbana valorizada. Os municípios agrupados no cluster 4 são aqueles que têm no FPM a principal fonte de receita. O padrão desse cluster são municípios pequenos, predominantemente rurais e que apresentam os piores resultados na cobrança de impostos.

Apesar de incluir-se no cluster do tipo 3, Vitória da Conquista mantém-se no limite, entre o cluster 3 e o cluster 4. A quota-parte do ICMS supera a participação do FPM na receita total em menos de dois pontos percentuais. O ICMS se destaca mais pela pujança comercial do que pela sua base industrial. A dinâmica industrial (e a atividade comercial, dela decorrente) é o que predomina entre os municípios do cluster 3. Com um incipiente e inexpressivo setor industrial, Vitória da Conquista encontra, nos serviços de saúde, na educação e no comércio, elementos determinantes para influenciar a sua região de articulação. O montante de ICMS, em 2014, (mais de 250 milhões de reais) é um indicador do potencial de arrecadação do município (BAHIA, 2014). Cabe salientar que as transferências correntes, no conjunto, representam 76,63\% das disponibilidades financeiras do município em 2014. Vitória da Conquista é, portanto, um município com fraco desempenho na arrecadação de seus tributos e mantém uma forte dependência das transferências. Apesar de inserirse no cluster 3, Vitória da Conquista conserva indicadores fiscais próximos dos indicadores de municípios pequenos (e, na maioria das vezes, pobres) que integram o cluster 4.

\section{Conclusões}

A pouca capacidade de arrecadação per capita de IPTU, a taxa de crescimento anual, consistente apenas com o crescimento urbano, e a fraca participação desse imposto nas receitas dos municípios 
e no produto municipal revelam um desempenho fiscal abaixo do potencial. A diferença nos valores per capita entre os médios e os grandes municípios é tão significativa que não pode ser explicada simplesmente pela desigualdade de renda ou pela dinâmica urbana. Além disso, entre 2013 e 2014, o IPTU per capita em Salvador mais que triplicou, o que sugere a possibilidade de ampliar as receitas com o esforço fiscal.

Um esforço fiscal maior pode elevar a arrecadação per capita em Vitória da Conquista, mas observa-se que o aumento da receita decorrente dessa ação não compensaria o ônus político, haja vista a representatividade residual do Imposto Predial e Territorial Urbano na composição da receita total. Isso evidencia o que preceitua a TEP, segundo a qual, o foco das decisões políticas não é o interesse público, mas a manutenção das condições para reproduzir o poder.

Em 2014, o Imposto Predial e Territorial Urbano representou apenas 2,34\% da receita total do município. Em face do conjunto das receitas, é irrelevante, portanto, o esforço fiscal na sua arrecadação. Ainda que dobrasse a sua cobrança, os ganhos financeiros não seriam substanciais, enquanto o ônus político poderia ser bastante elevado. Um aumento de 4\% nas transferências correntes seria superior a uma elevação de 100\% na arrecadação desse imposto. A dependência das transferências, nesse caso, desestimularia o esforço fiscal. Se a Planta Genérica de Valores dos imóveis tivesse sido atualizada de forma contínua ao longo das últimas décadas, o IPTU assumiria, hoje, maior importância no conjunto das receitas, tornando compensador (e não residual) o esforço fiscal. Atualizar a planta genérica para um único exercício fiscal é inviável, se forem considerados o impacto na renda dos contribuintes e no mercado imobiliário e os efeitos políticos decorrentes dessa ação.

A comparação dos indicadores das finanças públicas de Vitória da Conquista com a média das estatísticas de Tristão (2003), segundo a classificação dos tipos de clusters, revela que, embora o município tenha o perfil econômico das cidades médias, seu desempenho fiscal é incompatível com a sua estrutura produtiva. Vitória da Conquista distancia-se muito do conjunto de municípios que integram o cluster 4, no tocante aos aspectos sociais, demográficos, econômicos e à dinâmica urbana, mas aproxima-se do grupo no que se refere ao desempenho na arrecadação de IPTU. Por outro lado, embora formalmente integrante do cluster 3, e, apesar das semelhanças econômicas, sociais e urbanas, seu desempenho fiscal é bastante inferior à média do grupo.

A base econômica do município apresenta um potencial de arrecadação de IPTU ainda não explorado. Assim, é possível afirmar que o fraco desempenho fiscal se associa ao reduzido esforço na arrecadação. As evidências comprovam, portanto, a hipótese que norteia este estudo: o baixo desempenho de Vitória da Conquista na arrecadação do Imposto Predial e Territorial Urbano relaciona-se, por um lado, ao ônus político, que desestimula a atualização da Planta Genérica de Valores. Por outro, às transferências intergovernamentais, que tornam residual esse imposto e desestimulam o esforço fiscal.

\section{Referências}

AFONSO, José Roberto R.; ARAÚJO, Erika Amorim; NÓBREGA, Marcos Antonio Rios da. O IPTU no Brasil: um diagnóstico abrangente. Rio de Janeiro: FGV, 2013. (FGV Projetos/IDP; v. 4).

BAHIA (Estado). Secretaria da Fazenda do Estado da Bahia. Finanças públicas: repasse aos municípios. Salvador: SEFAZ, 2014. Disponível em: <http://www.sefaz.ba.gov.br/>. Acesso em: 15 dez. 2016. 
BERNABEL, Rodolpho T. Teoria da Escolha Pública: uma introdução crítica. 2009. 88 f. Dissertação (Mestrado em Ciências Políticas) - Faculdade de Filosofia, Letras e Ciências Humanas, Universidade de São Paulo, São Paulo, 2009.

BRASIL. Constituição (1988). Emenda constitucional n 29, de 13 de setembro de 2000. Brasília, DF: Casa Civil - Presidência da República, 2000. Disponível em: <http://www.planalto.gov.br/ ccivil_03/constituicao/emendas/emc/emc29.htm>. Acesso em: 08 set. 2016.

- Ministério da Fazenda. Centro de Estudos Tributários e Aduaneiros (CETAD). Carga Tributária no Brasil - 2014: Análise por tributo e base de incidência. Brasília, DF, outubro de 2015a.

. Secretaria do Tesouro Nacional. Finanças do Brasil-FINBRA STN/MF. Receita Municipal Anual - 2015: Dados Contábeis dos Municípios. Brasília, DF, 2015b. Disponível em:

<http://dados.gov.br/dataset/financas-publicas-anual/resource>. Acesso em: 11 set. 2016.

Acesso em: 14 out. 2016.

Transferências Constitucionais. Disponível em: <http://sisweb.tesouro.gov.br>.

INSTITUTO BRASILEIRO DE GEOGRAFIA E ESTATÍSTICA (IBGE). Estimativa da população para os municípios brasileiros. Brasília: Ministério do Planejamento, 2014. Disponível em: <http://www.ibge.gov.br/home/estatistica/populacao/estimativa2014/>. Acesso em: 11 set. 2016

Brasil em sintese: contas nacionais. Brasília: Ministério do Planejamento, 2015. Disponível em: <http://brasilemsintese.ibge.gov.br/contas-nacionais/pib-valores-correntes.html>. Acesso em: 14 set. 2016.

LOPES, R. P. M. A atualidade das instituições e a (in)eficiência das políticas para superação das desigualdades regionais: o caso do semiárido baiano. In: LUZÓN, José Luis; CARDIM, Márcia. (Org.). Problemas sociales y regionales en América Latina. Barcelona: Publicacions I Edicions de la Universitat de Barcelona, 2009, p. 167-191.

MAIA, Doralice S. Cidades Médias e Pequenas do Nordeste: Conferência de Abertura. In: LOPES, Diva Maria Ferlin; HENRIQUE, Wendel (Org.). Cidades médias e pequenas: teorias, conceitos e estudos de caso. Salvador: SEI, 2010. (Série estudos e pesquisas, 87).

MUSGRAVE, Richard A.; MUSGRAVE, Peggy B. Finanças públicas: teoria e prática. Rio de Janeiro: Campus, 1980.

PEREIRA, Paulo Trigo. A teoria da escolha pública (public choice): uma escolha neoliberal? Análise Social, Lisboa, v. 32, n. 141, $2^{\circ}$ sem., p. 419-442, 1997.

PREFEITURA MUNICIPAL DE VITÓRIA DA CONQUISTA (PMVC). Lei ñ 1972/2014, 13 de janeiro de 2014. Estima a receita e fixa a despesa do Município de Vitória da Conquista para o exercício financeiro de 2014 e dá outras providências.

SPOSITO, Maria Encarnação Beltrão. Para pensar as pequenas e médias cidades brasileiras. Belém: FASE/ICSA/UFPA, 2009. v 1. 
SUPERINTENDÊNCIA DE ESTUDOS ECONÔMICOS E SOCIAIS DA BAHIA. Boletim Técnico 2013. Salvador: SEI, 2014. Disponível em: <http://www.sei.ba.gov.br>. Acesso em: 11 set. 2016.

TRISTÃO, José Américo Martelli. A administração tributária dos municípios brasileiros: uma avaliação do desempenho da arrecadação. 2003. 172 f. Tese (Doutorado em Organização, Recursos Humanos e Planejamento) - EAESP/FGV, São Paulo, 2003. 